\title{
CONFIDENCIALIDAD EN LA CONTRATACIÓN ADMINISTRATIVA ELECTRÓNICA
}

\section{CONFIDENTIALITY IN ELECTRONIC ADMINISTRATIVE PROCUREMENT}

\section{PABLO SchiAVI}

Doctor en Derecho y Ciencias Sociales por la Facultad de Derecho de la Universidad de la República Oriental del Uruguay. Doctorando en Derecho Administrativo Iberoamericano por la Facultad de Derecho de la Universidad de la Coruña (en curso). Máster en Derecho Administrativo Económico por la Universidad de Montevideo (UM). Profesor Adjunto Grado 3 (I) de Derecho Público II y III (Derecho Administrativo y Derecho Procesal Constitucional, respectivamente); Profesor Asistente Grado 2 (I) de Derecho Público I y III (Derecho Constitucional y Derecho Procesal Constitucional, respectivamente) y Profesor Encargado del Taller de Análisis Critico de Derecho Constitucional en la Facultad de Derecho de la Universidad de la República. Profesor de Procedimientos Administrativos; Derecho Administrativo

Disciplinario; Información Pública y Datos Personales; Protección de Datos Personales en Salud;

Protección de Datos Personales Tributarios y Bancarios en el Máster de Derecho Administrativo Económico (MDAE) en la Facultad de Derecho de la Universidad de Montevideo. Profesor de Metodologia de la Investigación y Tesis I y II en LL.M. Máster en Derecho. Profesor de Datos Personales en Salud en el Máster en Dirección de Empresas de Salud (MDES) en la Escuela de Negocios de la Universidad de Montevideo (IEEM). Profesor de Derecho de la Información en la Facultad de Comunicación de

la Universidad de Montevideo. Diplomado en Desarrollo y Financiamiento de Infraestructuras por la Universidad Politécnica de Madrid. Certificado en Prevención del Lavado de Dinero y Financiamiento del Terrorismo por la Facultad de Derecho de la Universidad Católica del Uruguay. Coordinador Nacional por Uruguay de la Red lberoamericana de Contratación Pública (REDICOP). Miembro del Foro lberoamericano de Derecho Administrativo. Miembro del Instituto de Derecho Administrativo y del Instituto de Derecho

Constitucional en la Facultad de Derecho de la Universidad de la República. Miembro Titular de la Asociación Derecho Público del Mercosur. Miembro de la Red Internacional de Bienes Públicos (RIBP). Autor de libros y artículos sobre temas de su especialidad. ORCID: [https://orcid.org/0000-0001-7420-2471]. pablo.schiavi@schiavi.com.uy

Recebido em: 06.05.2021

Aprovado em: 06.06.2021 DOI: [https://doi.org/10.48143/rdai.18.ps]

\section{ÁreA do DIREITo: Administrativo}

RESUMEN: El propósito de este articulo es abordar la confidencialidad en la contratación pública electrónica, ya que la legislación vigente en Uruguay determina que la contratación pública debe
ABSTRACT: The purpose of this paper is to address confidentiality in electronic public procurement, since current legislation in Uruguay determines that public procurement must be guided, in a very 
guiarse, en una regla muy amplia, por el principio de transparencia, considerando que es el verdadero sustento de la contraer la democracia, lo que la convierte en el principal instrumento para combatir la corrupción. Ocurre que el ordenamiento juridico prevé excepciones, en las que la información se puede clasificar como secreta, reservada y confidencial, según lo define la legislación. Finalmente, aborda la modalidad de Apertura Electrónica para ser utilizada por la Administración Pública en sus contratos.

Palabras clave: Transparencia - La contratación pública - Apertura electrónica - Corrupción - Información. broad rule, by the principle of transparency, considering that it is the true basis of contracting democracy, which makes it the main instrument to combat corruption. It happens that the legal system foresees exceptions, in which the information can be classified as secret, reserved and confidential, as defined by the legislation. Finally, it addresses the Electronic Opening modality to be used by the Public Administration in its contracts.

Kerwords: Transparency - Public procurement Electronic opening - Corruption - Information.

SUMÁRIO: I. Transparencia y publicidad como regla en la contratación administrativa. Reserva o confidencialidad como excepción de interpretación estricta. II. Principios rectores de la contratación administrativa recogidos en la ley de contabilidad y administración financiera (TOCAF-2012) y en la ley de contratos de participación público privada. III. Limites al acceso a la información pública y sus proyecciones en la contratación administrativa. N. El secreto, la reserva y la confidencialidad en los procedimientos de contratación regulados en el TOCAF- 2012 como límite al acceso a la información pública. V. Confidencialidad en los procedimientos de compras y contrataciones estatales electrónicas: nuevas dimensiones de la transparencia ante los avances tecnológicos, informáticos y telemáticos. VI. Reflexiones finales. VII. Bibliografía.

\section{Transparencia y PUblicidad COMO REgLA EN LA CONTRATACIÓN ADMINISTRATIVA. RESERVA O CONFIDENCIALIDAD COMO EXCEPCIÓN DE INTERPRETACIÓN ESTRICTA}

La contratación administrativa es por esencia pública, lo cual implica que todos los procedimientos competitivos de contratación que realicen las administraciones públicas deben ser transparentes y la información debe estar al alcance de todos los ciudadanos, lo cual abarca los llamados a licitación, los pliegos de bases y condiciones generales y particulares, los adjudicatarios entre otros extremos.

La Ley $N^{\circ} 18.381$, de 17 de octubre de 2008, que tiene por objeto promover la transparencia de la función administrativa de todo organismo público, sea o no estatal, y garantizar el derecho fundamental de las personas al acceso a la información pública, en su artículo $5^{\circ}$, en sede de transparencia activa, dispone:

"Artículo 5. (Difusión de la información pública).- Los sujetos obligados deberán prever la adecuada organización, sistematización y disponibilidad 
de la información en su poder, asegurando un amplio y fácil acceso a los interesados.

Los organismos públicos, sean o no estatales, deberán difundir en forma permanente, a través de sus sitios web u otros medios que el órgano de control determine, la siguiente información mínima:

A) Su estructura orgánica.

B) Las facultades de cada unidad administrativa.

C) La estructura de remuneraciones por categoría escalafonaria, funciones de los cargos y sistema de compensación.

D) Información sobre presupuesto asignado, su ejecución, con los resultados de las auditorías que en cada caso corresponda.

E) Concesiones, licitaciones, permisos o autorizaciones otorgadas, especificando los titulares o beneficiarios de éstos.

F) Toda información estadística de interés general, de acuerdo a los fines de cada organismo.

G) Mecanismos de participación ciudadana, en especial domicilio y unidad a la que deben dirigirse las solicitudes para obtener información".

La información relativa a "Concesiones, licitaciones, permisos o autorizaciones otorgadas, especificando los titulares o beneficiarios de éstos" es esencialmente pública y más aún, es la información mínima que los sujetos obligados están obligados a publicar en los sitios webs oficiales sin necesidad que cualquier interesado la solicite.

Todo lo cual se ha potenciado con la creación de la Agencia de Compras y Contrataciones Estatales (ACCE) ${ }^{1}$ y de su portal $\mathrm{Web}^{2}$ donde las Administraciones Públicas publican la información referida a contrataciones de obras, bienes y servicios, de forma tal que constituya una herramienta de transparencia puesta a disposición de la ciudadanía ${ }^{3}$.

Es sustantivo recalcar este principio de transparencia que es sinónimo de la contratación administrativa al comienzo del presente trabajo ya que es el verdadero sostén de una contratación pública transparente, profesional y visible para

1. SCHIAVI, P. (2013). La Agencia de Compras y Contrataciones del Estado (ACCE): Desafíos de una nueva gestión en las compras y contrataciones del Estado. Estudios de Derecho Administrativo, (8), 113-159.

2. https://www.comprasestatales.gub.uy.

3. SCHIAVI, P. (2013). La Agencia de Compras y Contrataciones del Estado (ACCE): Desafíos de una nueva gestión en las compras y contrataciones del Estado. Estudios de Derecho Administrativo, (8), 113-159. 
toda la ciudadanía, principal escudo en la lucha contra la corrupción que aflora en esta materia, como punto de partida para abordar lo que debe ser la excepción y no la regla en sede de procedimientos competitivos de contratación.

En tal sentido y con claridad meridiana lo señala DURÁN MARTíNEZ (2012) ${ }^{4}$ al afirmar que el derecho de acceso a la información pública no es ilimitado. Pero por tratarse de un derecho humano, las limitaciones sólo pueden disponerse por ley dictada por razones de interés general, o provenir de otro derecho humano que es preciso conciliar. En virtud de lo expuesto, cabe afirmar que el acceso a la información es el principio, la limitación es de excepción. Por tanto, las normas que limitan el acceso, como toda norma de excepción, son de interpretación estricta, como acertadamente lo establece el artículo 8 de la ley $\mathrm{N}^{\circ} 18.381$.

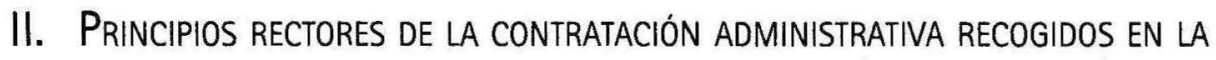 LEY DE CONTABILIDAD Y ADMINISTRACIÓN FINANCIERA (TOCAF-2012) Y EN LA LEY DE CONTRATOS DE PARTICIPACIÓN PÚBLICO PRIVADA}

El Texto Ordenado de Contabilidad y Administración Financiera, aprobado por el decreto $\mathrm{N}^{\circ} 150 / 012$, de 11 de mayo de 2012 (TOCAF-2012), por su artículo 149 enumeró una serie de principios en materia de contratación administrati$\mathrm{va}^{5}$, entre los cuales se destaca el principio de transparencia ( $\mathrm{H}$. Transparencia).

Misma postura legislativa adopta la Ley $\mathrm{N}^{\circ} 18.786$, de 19 de julio de 2011, que regula los contratos de participación público-privada (P.P.P.), que refiere a los principios de transparencia y publicidad.

Al respecto DURÁN MARTÍNEZ (2018) sostiene que el TOCAF no es este el único texto normativo que enumera principios en materia de contratos administrativos. En la misma línea el artículo 4 de la ley $N^{\circ} 18.786$, con relación a los contratos de participación público-privada (P.P.P.) enumera una serie de principios: entre ellos "a) transparencia y publicidad.".

Los principios enunciados en nuestra Ley de Contabilidad y Administración Financiera no son una originalidad de nuestro derecho positivo ${ }^{6}$.

4. DURÁN MARTÍNEZ, A. (2012). Derecho a la protección de datos personales y al acceso a la información pública hábeas data: Leyes no. 18.331, de 11 de agosto de 2008 y no. 18.381, de 17 de octubre de 2008. (2a.ed.act.ampl). Montevideo: Amalio M. Fernández; p.107.

5. DURÁN MARTÍNEZ, A. (2018). "Principios rectores de la contratación administrativa. Incidencia en la ejecución de los contratos administrativos". Estudios de Derecho Administrativo, (17), 5-39.

6. DURÁN MARTÍNEZ, A. (2013). "Principios de la contratación administrativa..."; loc. cit., p. 57. 
Así, por ejemplo ${ }^{7}$ : a) el artículo 1 de la ley española $N^{0} 30 / 2007$, de 30 de octubre, con la misma u otra terminología recoge varios de esos principios; b) el artículo 3 de la ley brasileña $\mathrm{N}^{\circ} 8.666$, de 21 de junio de 1943, con relación a las licitaciones menciona los siguientes principios: de legalidad, impersonalidad, moralidad, igualdad, publicidad, probidad administrativa, vinculación al instrumento convocatorio, juicio objetivo y los que derivan de ellos; c) el artículo 1 de la ley de adquisiciones y contrataciones de la Administración Pública de la República de El Salvador (D.L. No 868, de 5 de abril de 2000) enumera los siguientes principios y valores: no discriminación, publicidad, libre competencia, igualdad, ética, transparencia, imparcialidad, probidad, centralización normativa y descentralización operativa.

La doctrina recoge también la mayoría de ellos ${ }^{8}$.

El principio de transparencia fue agregado expresamente por el artículo 52 de la ley N. ${ }^{\circ} 18.834$ (2011) como uno de los "principios generales de actuación y contralor en materia de la Ley de Contabilidad y Administración Financiera".

Pero eso no quiere decir que con anterioridad no existía 9 .

El principio de transparencia rige sin necesidad de texto expreso que lo imponga porque hace a la esencia de la buena administración. Es más, como lo

7. DURÁN MARTÍNEZ, A. (2013). "Principios de la contratación administrativa..."; loc. cit., p. 57.

8. DURÁN MARTÍNEZ, A. (2013). "Principios de la contratación administrativa..."; loc. cit., p. 58. Véase, por ejemplo: en Argentina, con relación a los principios de selección del contratista CASSAGNE enumeró los siguientes principios: $a^{\prime}$ ) de concurrencia y de competencia; a") de proporcionalidad y razonabilidad; a") de eficiencia; IV) de publicidad, difusión y transparencia; V) de responsabilidad; VI) de igualdad de tratamiento para interesados y para oferentes; en Brasil, con relación a la licitación pública, BANDEIRA DE MELLO indica los siguientes principios: b') competitividad; b") isonomía; b"') publicidad; IV) respeto de las condiciones prefijadas en el pliego; V) posibilidad del postulante de controlar el cumplimiento de los principios anteriores; en Colombia, Libardo RODRÍGUEZ enumera los siguientes principios: c') de transparencia; c") de economía; $c^{\text {"') }}$ de responsabilidad; IV) del equilibrio económico financiero del contrato; V) de interpretación de la contratación estatal, en el sentido de que en la interpretación de las normas sobre contratos y de las cláusulas de los mismos, se tendrán en consideración los fines y los principios de que trata el estatuto, los mandatos de la buena fe y la igualdad y equilibrio entre prestaciones y derechos que caracteriza a los contratos conmutativos; VI) el de la selección objetiva; en Costa Rica, ROJAS FRANCO destaca los principios de igualdad, publicidad y transparencia; en España, RODRÍGUEZ-ARANA MUÑOZ, aludió a los principios de objetividad, imparcialidad, publicidad, concurrencia, igualdad de trato, no discriminación, equidad, transparencia y de la cláusula del progreso.

9. DURÁN MARTÍNEZ, A. (2013). "Principios de la contratación administrativa..."; loc. cit., p. 62. 
demostró CAJARVILLE PELUFFO, la transparencia se relaciona con muchos de los principios que rigen la contratación administrativa ${ }^{10}$.

A nivel continental esa preocupación se pone de manifiesto especialmente en la Convención Interamericana Contra la Corrupción, suscrita en Caracas el 29 de marzo de 1996 y aprobada en Uruguay por ley $N^{\circ} 17.008$, de 25 de setiembre de 1998, que contiene disposiciones especificas en materia de contratos del Estado (artículo III.5), precisamente para asegurar la transparencia ${ }^{11}$

En sintonía con la Convención Interamericana nuestro país dictó la ley $\mathrm{N}^{\circ} 17.060$, de 23 de diciembre de 1998, conocida como ley anticorrupción. El Capítulo III denominado control Social apunta a asegurar la transparencia en la Administración Pública ${ }^{12}$.

De este capítulo interesa especialmente a efectos de nuestro tema los artícu$\operatorname{los} 5 \mathrm{y} 7^{13}$.

El artículo $5^{\circ}$ establece: "Los organismos públicos darán amplia publicidad a sus adquisiciones de bienes y contrataciones de servicios, de acuerdo a las pautas que fije el Poder Ejecutivo -o el órgano jerarca, en su caso- al reglamentar la presente ley."

El artículo $7^{\circ}$ establece:

"Los actos, documentos y demás elementos relativos a la función pública pueden ser divulgados libremente, salvo que por su naturaleza deban permanecer reservados o secretos o hayan sido declarados tales por ley o resolución fundada. En todo caso, bajo la responsabilidad a que hubiese lugar por derecho."

El artículo 22 de la ley $N^{\circ} 17.296$ de 25 de enero de 2001, recoge también el principio de transparencia ${ }^{14}$. En tal sentido establece:

"Los órganos y organismos comprendidos en el artículo 451 de la Ley $\mathrm{N}^{\circ} 15.903$, de 10 de noviembre de 1987 , se regirán por los principios de transparencia e información de la ejecución financiera, debiendo informar a la opinión pública sobre su gestión financiera, con una periodicidad no superior a

10. DURÁN MARTÍNEZ, A. (2013). "Principios de la contratación administrativa..."; loc. cit., p. 62.

11. DURÁN MARTÍNEZ, A. (2013). "Principios de la contratación administrativa..."; loc. cit., p. 62.

12. DURÁN MARTÍNEZ, A. (2013). "Principios de la contratación administrativa..."; loc. cit., p. 62.

13. DURÁN MARTÍNEZ, A. (2013). "Principios de la contratación administrativa..."; loc. cit., p. 62.

14. DURÁN MARTÍNEZ, A. (2013). "Principios de la contratación administrativa..."; loc. cit., p. 
los tres meses y en los plazos, forma y condiciones que establezca la reglamentación que dicte el Poder Ejecutivo.

De dicha información se remitirá copia a la Asamblea General, al Tribunal de Cuentas y al Ministerio de Economía y Finanzas. En caso de incumplimiento, se dará cuenta a la Asamblea General."

Ambos aspectos sin duda confluyen y contribuyen a incorporar a texto expreso el principio de transparencia en la nueva ley al enumerar los principios de la contratación administrativa, principio que, como ya se ha visto, existía y estaba comprendido en el de buena administración ${ }^{15}$.

\section{LIMITES AL ACCESO A LA INFORMACIÓN PÚBLICA Y SUS PROYECCIONES EN LA CONTRATACIÓN ADMINISTRATIVA}

En el Capítulo Primero "Disposiciones Generales" de la Ley N 18.381 de 17 de octubre de 2008 , se dispone expresamente que la ley tiene por objeto promover la transparencia de la función administrativa de todo organismo público, sea o no estatal, y garantizar el derecho fundamental de las personas al acceso a la información pública.

Sobre el punto señala Augusto DURÁN MARTÍNEZ ${ }^{16}$ que "la ley se alinea expresamente con la corriente doctrinaria que vincula el derecho al acceso a la información a la transparencia. Pero eso no significa negar la vinculación que tiene nuestro tema con la democracia. En efecto, transparencia y democracia están últimamente vinculadas, pues no puede haber democracia sin transparencia".

De acuerdo con los "Los Principios del Comité Jurídico Interamericano (2008)", el derecho de acceso a la información refiere a toda información significante, cuya definición debe ser amplia, incluyendo toda la que es controlada y archivada en cualquier formato o medio por los Estados ${ }^{17}$.

Habiendo precisado el concepto de la información pública, la Ley hace hincapié en su difusión. El artículo $5^{\circ}$ de la Ley incorpora las denominadas obligaciones de transparencia activa.

15. DURÁN MARTÍNEZ, A. (2013). "Principios de la contratación administrativa..."; loc. cit., p.

16. DURÁN MARTÍNEZ, A. (2012). Derecho a la protección de datos personales y al acceso a la información pública hábeas data ... loc. cit., p. 101 y siguientes.

17. SCHIAVI, P. (2016). Régimen jurídico de la acción de acceso a la información pública en el Uruguay. En: Estudios de información pública y datos personales: recopilación de trabajos de investigación de los cursos de postgrado 2014-2015. (pp.21-61). Montevideo: Universidad de Montevideo. Facultad de Derecho. 
En forma acertada, Cristina VÁZQUEZ señala que "transparencia implica apertura, comunicación y rendición de cuentas, y el acceso a la información pública constituye instrumento fundamental para su realización" 18 .

Las excepciones a la información pública, al decir del artículo 8 de la Ley, serán de interpretación estricta y comprenderán aquellas definidas como secretas por la ley y las que se definan seguidamente como de carácter reservado y confidencial.

Al respecto enseña Carlos E. DELPIAZZO ${ }^{19}$ que "desde el punto de vista material o del contenido, a juicio del Instituto, hay un triple señalamiento importante a indicar respecto a las excepciones: con el principio de publicidad, con relación al sistema de control que se implementa y con referencia al equilibrio que debe existir entre el acceso a la información administrativa y la protección de los datos personales que puedan estar contenidos en dicha información administrativa".

\section{A.- Información secreta. -}

Información secreta ${ }^{20}$ es la así definida por la Ley. Cristina VÁZQUEZ ${ }^{21}$ señala como ejemplos los casos del secreto tributario ${ }^{22}$, del secreto bancario ${ }^{23}$ o del secreto estadístico ${ }^{24}$, entre otros.

A los efectos del acceso a la información pública, apunta Augusto DURÁN MARTÍNEZ que no deben considerarse secretas las informaciones así consideradas por otros actos jurídicos infravalentes a la ley ${ }^{25}$.

18. VAZZUEZ, C. (2011). El régimen jurídico del acceso a la información pública y la protección de los datos personales. Revista de Derecho y Tribunales, (15), 59-109.

19. Comisión de Educación y Cultura de la Cámara de Senadores de la República Oriental del Uruguay; Carpeta $N^{\circ} 541 / 2006$; Versión taquigráfica de la reunión realizada el día 23 de noviembre de 2006, Palabras del Dr. Carlos E. DELPIAZZO, citado en SCHIAVI, P. (2012). El control del acceso a la información pública y de la protección de datos personales en el Uruguay. Montevideo: Universidad de Montevideo. Facultad de Derecho.

20. Información secreta definida por Ley: Secretos comerciales-industriales; Secretos que deben guardar los funcionarios; Secreto de las comunicaciones; Secreto de las comunicaciones; Secreto bancario - tributario; Secreto estadístico; Secreto profesional; Secreto político y militar.

21. VÁZQUEZ, C. (2011). El régimen jurídico del acceso a la información pública y la protección de los datos personales... loc. cit., p. 80 y siguientes.

22. Código Tributario, artículo 47.

23. Decreto Ley $N^{\circ} 15.322$ de 17 de setiembre de 1982, artículo 25. Secreto bancario-tributario.

24. Ley $\mathrm{N}^{\circ} 16.616$ de 20 de octubre de 1994, artículo 3. Secreto estadístico.

25. DURÁN MARTÍNEZ, A. (2012). Derecho a la protección de datos personales y al acceso a la información pública hábeas data ... loc. cit., p. 110. 
Por ejemplo, en 2015, la compra del nuevo sistema de vigilancia e interceptación de telecomunicaciones "El Guardián" fue realizado por el Ministerio del Interior bajo el procedimiento excepcional de compra directa fundada en el secreto ${ }^{26}$.

B.- Información reservada. -

El artículo $9^{\circ}$ regula la información reservada, debiendo destacar que la redacción original del artículo sufrió modificaciones posteriores: el Literal g) y los incisos $2^{\circ}$ ), $3^{\circ}$ ) y $4^{\circ}$ ) fueron agregados por la Ley $\mathrm{N}^{\circ} 19.178$ de 27 de diciembre

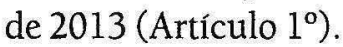

"Artículo 9. (Información reservada). - Como información reservada podrá clasificarse aquella cuya difusión pueda:

A) Comprometer la seguridad pública o la defensa nacional.

B) Menoscabar la conducción de las negociaciones o bien, de las relaciones internacionales, incluida aquella información que otros estados u organismos internacionales entreguen con carácter de reservado al Estado uruguayo.

C) Dañar la estabilidad financiera, económica o monetaria del país.

D) Poner en riesgo la vida, la dignidad humana, la seguridad o la salud de cualquier persona.

E) Suponer una pérdida de ventajas competitivas para el sujeto obligado o pueda dañar su proceso de producción.

F) Desproteger descubrimientos cientificos, tecnológicos o culturales desarrollados o en poder de los sujetos obligados.

G) Afectar la provisión libre y franca de asesoramientos, opiniones o recomendaciones que formen parte del proceso deliberativo de los sujetos obligados hasta que sea adoptada la decisión respectiva, la cual deberá estar documentada.

La clasificación de la información reservada deberá realizarse por el sujeto obligado en el momento en que esta se genere, obtenga o modifique, mediante resolución debidamente fundada y motivada, en la que se demuestre la existencia de elementos objetivos que permitan determinar que la divulgación de la misma genera un riesgo claro, probable y específico de daño al interés público protegido, de acuerdo con las excepciones referidas en el presente artículo. Excepcionalmente, la información podrá clasificarse como reservada en el momento en que se reciba una solicitud de acceso a la misma. En este caso,

26. SCHIAVI, P. (2016). Régimen jurídico de la acción de acceso a la información pública en el Uruguay. En: Estudios de información pública y datos personales: recopilación de trabajos de investigación de los cursos de postgrado 2014-2015. (pp.21-61). Montevideo: Universidad de Montevideo. Facultad de Derecho. 
la resolución fundada que disponga la clasificación de la información deberá remitirse en el plazo de cinco días hábiles a la Unidad de Acceso a la Información Pública, la que, en ejercicio de su cometido de control, solicitará al sujeto obligado su desclasificación si la misma no se ajustare a lo dispuesto en el presente artículo. En cualquier caso, el plazo de reserva comenzará a computarse a partir de que la información pudo ser clasificada.

En todo momento, la Unidad de Acceso a la Información Pública podrá tener acceso a la información clasificada para evaluar la regularidad de su clasificación".

Respecto de la clasificación de la información como reservada, debe precisarse que las reservas genéricas de información no son ajustadas a la Ley y su decreto reglamentario por tanto la clasificación debe realizarse en forma particular, debiendo descartarse la realización de una reserva genérica.

Tal como dispone expresamente el artículo 25 del decreto reglamentario, la clasificación de la información como reservada requiere la prueba del daño.

C.- Información confidencial. -

Se considera información confidencial ${ }^{27}$ la regulada en el artículo $10^{\circ}$ de la Ley.

"Artículo 10. (Información confidencial).- Se considera información confidencial:

1) Aquella entregada en tal carácter a los sujetos obligados, siempre que:

A) Refiera al patrimonio de la persona.

B) Comprenda hechos o actos de carácter económico, contable, jurídico o administrativo, relativos a una persona física o jurídica, que pudiera ser útil para un competidor.

C) Esté amparada por una cláusula contractual de confidencialidad.

II) Los datos personales que requieran previo consentimiento informado.

Tendrán el mismo carácter los documentos o secciones de documentos que contengan estos datos".

De acuerdo con lo dispuesto en el artículo 29 del decreto reglamentario no será considerada información confidencial la que por disposiciones legales se encuentre en registros públicos y la que se encuentre en fuentes de acceso público. En este caso, se dará a conocer a quien la solicita: fuente, lugar y forma de acceder a la información que se pretende.

27. Decreto $N^{\circ} 232 / 010$ de 2 de agosto de 2010. CAPÍTULO III - Información confidencial Artículo $28^{\circ}$. - Información confidencial. 
Por su parte el artículo 30 del decreto reglamentario regula la Información confidencial entregada por particulares disponiendo que cuando los particulares entreguen a los sujetos obligados información confidencial, deberán señalar los documentos o secciones en los que se contenga tal información. También deberán presentar un "resumen no confidencial" breve y conciso. En caso de que, la naturaleza de la información impida elaborarlo, se explicitará tal imposibilidad ante la autoridad competente.

Sobre el punto expresa Augusto DURÁN MARTÍNEZ que, aunque el decreto dice algo que no dice la ley, no creo que sea ilegal puesto que no prevé la consecuencia del incumplimiento. No toda diferencia implica ilegalidad ${ }^{28}$.

Respecto al período de la clasificación, el artículo 32 del decreto reglamentario dispone que la información confidencial no está sujeta a plazos de vencimiento y tendrá ese carácter en forma indefinida.

D.- Principales diferencias entre la información reservada y la información confidencial.

Por Resolución N ${ }^{\circ}$ 8/2010 de 25 de febrero de 2010, el Consejo Ejecutivo de la Unidad de Acceso a la Información Pública aprobó el Manual sobre Clasificación de información en poder de los sujetos obligados por la Ley de Acceso a la Información Pública, al que denomina "Manual para la orientación sobre clasificación de la información pública ${ }^{29 ،}$.

En la práctica, y teniendo presente que, en materia de clasificación de la información, las mayores dificultades giran en torno a las diferencias entre la información reservada y la información confidencial, entiendo que éste nuevo Manual arroja luz sobre esta cuestión.

En el Capítulo 3 "Información Confidencial", numeral VI del Manual referido, se inserta un Cuadro de las principales diferencias entre la información reservada y la información confidencial de la siguiente forma:

a) Respecto de la Información reservada, se hace referencia a "materias que deben protegerse para el buen funcionamiento del Estado o debido a razones de interés general o colectivo". Mientras que, respecto a la información confidencial, "se protege directamente el derecho a la vida privada, los datos personales, el patrimonio de las personas físicas o jurídicas, y los datos empresariales útiles para la competencia".

28. DURÁN MARTÍNEZ, A. (2012). Derecho a la protección de datos personales y al acceso a la información pública hábeas data ... loc. cit., p. 115.

29. https://www.gub.uy/unidad-acceso-informacion-publica/sites/unidad-acceso-informacion-publica/files/documentos/publicaciones/Gu\%C3\%ADa_clasificaci\%C3\%B3n\%2BVF\%2B\%281\%29.pdf. 
b) En cuanto a la información reservada, "se trata de información en poder del órgano público, que versa sobre cuestiones de interés de la sociedad en general". En cambio, en cuanto a la información confidencial, "se trata de información entregada por los particulares al Estado. Los titulares son los dueños de la información, por lo que tienen derecho a decidir sobre su destino y difusión".

c) En cuanto a la oponibilidad, la reserva "es oponible frente a cualquier particular, salvo ciertas excepciones como cuando median razones de interés público, una orden judicial, o nos encontramos ante las hipótesis previstas en el art. 12 de la Ley"; en cambio la confidencialidad "es oponible a todos menos al titular de la información. La excepción no es oponible a terceros cuando median razones de interés público, una orden judicial, o nos o nos encontramos ante las hipótesis previstas en el art. 12 de la Ley".

d) En cuanto al plazo, "la reserva es necesariamente temporal. Está sujeta a plazo y a la existencia de causas probadas, mientras éstas se mantienen". En cambio, la confidencialidad "permanece con ese carácter de manera indefinida".

e) En cuanto al carácter de la información, la información reservada "sigue siendo pública sólo que debido a causas justificadas debe reservarse del conocimiento de los interesados por un plazo determinado". En cambio, la información confidencial "no es pública sino privada ya que pertenece a los individuos".

f) En cuanto a la clasificación, la clasificación de la información reservada "se realiza en el momento en que se genera, o produce un expediente o documento, mediante resolución fundada del sujeto obligado, firmada por el Jerarca o quien ejerza funciones delegadas". En cambio, la clasificación de la información confidencial, se realiza mediante "resolución fundada del jerarca o quien ejerza funciones delegadas, en el momento en que se recibe, se genera o produce un expediente o documento, y además a partir de la recepción de una solicitud de acceso a la información, para el caso que no se hubiera clasificado antes".

\section{El SECRETO, LA RESERVA Y LA CONFIDENCIALIDAD EN LOS PROCEDIMIENTOS DE CONTRATACIÓN REGULADOS EN EL TOCAF- 2012 COMO LIMITE AL ACCESO A LA INFORMACIÓN PÚBLICA}

En los procedimientos de contratación regulados en el TOCAF-2012, aprobado por el Decreto $N^{\circ} 150 / 012$, de 11 de mayo de 2012, existen notas de secreto, reserva y confidencialidad, a las cuales haremos referencias en el presente apartado.

\section{1.- Información secreta. -}

El numeral $8^{\circ}$ del literal C) del artículo 33 del TOCAF-2012 refiere a contrataciones que deban "mantenerse en secreto": 
"Artículo 33: Las contrataciones se realizarán mediante licitación pública u otro procedimiento competitivo expresamente previsto, de acuerdo a lo que mejor se adecue a su objeto, a los principios generales de la contratación administrativa y de acuerdo a lo previsto en la normativa vigente,

No obstante, podrá contratarse:

C) Directamente o por el procedimiento que el ordenador determine por razones de buena administración, en los siguientes casos de excepción:

8) Cuando las circunstancias exijan que la operación deba mantenerse en secreto".

El artículo 33 del TOCAF-2012 sienta el principio - cada vez más debilitadode que las contrataciones deben efectuarse por licitación pública.

El ya incontable número de excepciones que hoy alcanzan a 40 demuestra que, lamentablemente, lo que es y debería ser la regla ya ha dejado de serlo.

Dentro de esas excepciones, el numeral 8) del Literal C) del artículo 33 del TOCAF - 2012 refiere a contrataciones que deben mantenerse en secreto con una motivación vaga justificada en "... Cuando las circunstancias exijan...".

Estamos dentro de uno de los límites al acceso a la información pública tal cual lo dispone la Ley $\mathrm{N}^{\circ} 18.381$, de 17 de octubre de 2008, que en su artículo $8^{\circ}$ dispone que "Las excepciones a la información pública serán de interpretación estricta y comprenderán aquellas definidas como secretas por la ley y las que se definan seguidamente como de carácter reservado y confidencial".

La fuente del artículo 33 del TOCAF-2012 es la Ley $N^{\circ} 15.903$, de 10 de noviembre de 1987, artículo 482 que ha sufrido innumerables modificaciones a lo largo del tiempo ${ }^{30}$.

Partiendo de la premisa de que la transparencia es la regla y los secretos deben ser la excepción, y a pesar de la redacción poco feliz del numeral 8), entendemos que el acto administrativo que se ampare en el numeral 8) debe ser debidamente fundado y motivado en razones de interés general que permitan exceptuar que la

30. Fuente IMPO: Ley 15.903 de 10/nov/987, artículo 482 con la redacción dada por los artículos 653 de la ley 16.170 de 28/dic/990; 738 de la ley 16.736 de 5/ene/996, 27 , de la ley 17.296 de 21/feb/001, 429 de la ley 17.930 de 19/dic/005, 26 de la ley 18.046 de 24/oct/006, 108 de la ley 18.172 de 31/ago/007, 11 de la ley 18.195 de 14/ nov/007, 407 y 506 de la ley 18.362 de 6/oct/008; 16, 18 y 250 de la ley 18.834 de 4/nov/011, y leyes $17.088 \mathrm{de} 30 / \mathrm{abr} / 999$, artículo $6 ; 17.296 \mathrm{de} 21 / \mathrm{feb} / 001$ artículos 404 y 494; 17.978 de 26/jun/006, artículo 8 y 18.874 de 23/dic/011, artículo 14; 18.172 de 31/ago/007 artículo 276; 18.597 de 21/set/009, artículo 25; 18.719 de $27 /$ dic/010, artículo $692 ; 18.829$ de $24 /$ oct/011, artículo 19 y 18.834 de 4/nov/011, artículos 17 y 197. 
contratación se realice fuera del régimen de publicidad y transparencia típico de las contrataciones públicas.

2.- Información reservada. -

A) Contrataciones de bienes o servicios, cualquiera sea su modalidad, por parte de los entes autónomos y servicios descentralizados integrantes del dominio industrial, comercial y financiero del Estado, destinada a servicios que se encuentren de hecho o de derecho en regímenes de libre competencia.

El literal C) del Artículo 44 del TOCAF-2012 dispone que las compras realizadas al amparo de la excepción establecida por el literal C) numeral 22) del Artículo 33 de este Texto Ordenado, podrán clasificarse como reservadas por el organismo.

"Artículo 44: Sin perjuicio de las excepciones establecidas en los artículos 33 y 45 del presente Texto Ordenado, amplíase para los Entes Autónomos y Servicios Descentralizados del dominio industrial y comercial del Estado, comprendidos en el artículo 221 de la Constitución de la República, a \$ 30:000.000 (treinta millones de pesos uruguayos) el tope de licitación abreviada y a $\$ 750.000$ (setecientos cincuenta mil pesos uruguayos) el tope de compra directa, siempre que tengan:

A) Un buen sistema de gestión y eficaz control interno en las áreas vinculadas a las contrataciones.

B) Estén comunicados electrónicamente con el Registro Único de Proveedores del Estado.

C) Publiquen todo lo relativo a sus contrataciones superiores al límite de su procedimiento de compra directa en el sitio web de Compras y Contrataciones Estatales contribuyendo a la transparencia de su sistema, de acuerdo con lo que establezca la reglamentación, la que podrá modificar ese límite. Las compras realizadas al amparo de la excepción establecida por el literal C) numeral 22) del Artículo 33 de este Texto Ordenado, podrán clasificarse como reservadas por el organismo.

Este régimen podrá ser suspendido por decisión fundada del Poder Ejecutivo, con el asesoramiento de la Agencia de Compras y Contrataciones del Estado y previo dictamen del Tribunal de Cuentas, si evalúa que no se cumplen las condiciones precedentes, lo que deberá declarar expresamente en la resolución respectiva.

El Poder Ejecutivo, con el asesoramiento de la Agencia de Compras y Contrataciones del Estado y previo dictamen del Tribunal de Cuentas, podrá autorizar este régimen, total o parcialmente, a otros organismos públicos que cumplan dichos requisitos y cuando sea conveniente para la buena administración.

Cuando no exista acuerdo entre el Poder Ejecutivo y el Tribunal de Cuentas o no haya dictamen de éste luego de sesenta días de solicitado, la resolución del Poder Ejecutivo será remitida a conocimiento de la Asamblea General". 
La fuente del artículo 44 del TOCAF-2012 es la Ley $N^{\circ} 15.903$, de 10 de noviembre de 1987, artículo 485 con la redacción dada por el artículo 26 de la Ley $\mathrm{N}^{\circ} 18.834$ de 4 de noviembre de 2011, con lo cual estamos ante una reserva de fuente legal y no administrativa.

Al respecto el numeral 22) del literal C) del del Artículo 33 del TOCAF-2012 refiere a contrataciones de bienes o servicios, cualquiera sea su modalidad, por parte de los entes autónomos y servicios descentralizados integrantes del dominio industrial, comercial y financiero del Estado, destinada a servicios que se encuentren de hecho o de derecho en regímenes de libre competencia.

"Artículo 33: Las contrataciones se realizarán mediante licitación pública u otro procedimiento competitivo expresamente previsto, de acuerdo a lo que mejor se adecue a su objeto, a los principios generales de la contratación administrativa y de acuerdo a lo previsto en la normativa vigente.

No obstante, podrá contratarse:

C) Directamente o por el procedimiento que el ordenador determine por razones de buena administración, en los siguientes casos de excepción:

22) La contratación de bienes o servicios, cualquiera sea su modalidad, por parte de los entes autónomos y servicios descentralizados integrantes del dominio industrial, comercial y financiero del Estado, destinada a servicios que se encuentren de hecho o de derecho en regímenes de libre competencia. Las impugnaciones o recursos que en tales casos se interpusieran, en cualquier etapa del procedimiento, no tendrán efecto suspensivo, salvo que así lo resuelva el jerarca de la empresa contratante."

B) Confidencialidad de la información de las ofertas hasta el acto de Apertura: responsabilidad de la Administración Contratante.

El Artículo 63 del TOCAF-2012 regula la forma de presentación de las ofertas, las condiciones exigidas, la concordancia que deben guardar con el Pliego de Condiciones particulares, y consagra en forma expresa una responsabilidad para la Administración Contratante en cuanto al resguardo de las ofertas utilizando los procedimientos y tecnologías que aseguren la confidencialidad de la información de tal forma que sea inviolable hasta el momento fijado para su apertura.

"Artículo 63: Los oferentes deberán presentar sus ofertas en las condiciones que se establezca en los pliegos respectivos, pudiendo agregar cualquier otra información complementaria pero sin omitir ninguna de las exigencias esenciales requeridas.

Las ofertas deberán ajustarse razonablemente a la descripción del objeto requerido, teniendo en cuenta la complejidad técnica del mismo. 
Se considerará que las condiciones técnicas establecidas en el pliego de condiciones particulares tienen carácter indicativo para la consecución del objeto del llamado.

Si el pliego de condiciones particulares así lo autoriza, podrán presentarse modificaciones, alternativas o variantes, inclusive sin presentarse la propuesta básica.

Las ofertas podrán presentarse personalmente contra recibo, en el lugar habilitado al efecto, o por correo, fax, en línea a través de los sitios web de compras estatales $\mathrm{u}$ otros medios remotos de comunicación electrónica según lo disponga el llamado, no siendo de recibo si no llegaren cumpliendo el plazo, lugar y medio establecido. En todos los casos será responsabilidad de la administración contratante el resguardo de las ofertas utilizando los procedimientos y tecnologías que aseguren la confidencialidad de la información de tal forma que sea inviolable hasta el momento fijado para su apertura".

La fuente del artículo 63 del TOCAF-2012 es la Ley No 15.903 , de 10 de noviembre de 1987, artículo 502 con la redacción dada por el artículo 36 de la Ley $\mathrm{N}^{\circ} 18.834$ de 4 de noviembre de 2011.

Una violación de la confidencialidad de la información de las ofertas, en tanto inviolable, hasta el acto de apertura, viciaría en forma irremediable el procedimiento de contratación en curso, más allá de la responsabilidad de la Administración.

C) Información confidencial en las ofertas: límite temporal.

El Artículo 65 del TOCAF-2012 regula la apertura de las ofertas que deberá hacerse en forma pública y las cuestiones relativas a la admisibilidad de las ofertas con posibilidad de salvar aquellos defectos que no se consideren apartamientos sustanciales.

"Artículo 65: La apertura de las ofertas se hará en forma pública en el lugar, día y hora fijados en las publicaciones en presencia de los funcionarios que designe a tal efecto la Administración pública licitante y de los oferentes o sus representantes que deseen asistir.

Abierto el acto no podrá introducirse modificación alguna en las propu pudiendo, no obstante, los presentes formular las manifestaciones, acla1 nes o salvedades que deseen.

En dicho acto no se podrá rechazar la presentación de ninguna propues perjuicio de su invalidación posterior y se controlará si en las propuestas adjuntado la garantía constituida, cuando ello correspondiera.

Finalizado el acto se labrará acta circunstanciada que será firmada por lo: cionarios actuantes $\mathrm{y}$ los oferentes que lo deseen hacer, quienes podrán ........ consignadas las constancias que estimen necesarias. 
La admisión inicial de una propuesta no será obstáculo a su rechazo si se constataren luego defectos que violen los requisitos legales o aquellos sustanciales contenidos en el respectivo pliego.

Se consideran apartamientos sustanciales aquellos que no pueden subsanarse sin alterar materialmente la igualdad de los oferentes.

La Administración podrá otorgar a los proponentes un plazo máximo de dos dias hábiles para salvar los defectos, carencias formales o errores evidentes $o$ de escasa importancia; este plazo podrá ampliarse para el caso de proveedores del exterior y en tal caso se aplicará a todos los oferentes.

El plazo antes mencionado no se otorgará cuando a juicio de la Administración se altere materialmente la igualdad de los oferentes, cuando existan defectos o errores habituales en un oferente determinado, o cuando se presuma la existencia de alguna maniobra destinada a obtener una ventaja indebida.

La apertura de las licitaciones electrónicas se efectuará en forma automática y el acta se remitirá a la dirección electrónica de los oferentes, de acuerdo con lo establecido en la reglamentación.

Los oferentes que así lo deseen podrán requerir a la Administración que le facilite copia o archivo electrónico de las ofertas presentadas para su análisis. El costo será de cargo del peticionario.

En el contenido de las ofertas se considerarán informaciones confidenciales, siempre que sean entregadas en ese carácter (artículo 10 de la Ley $\mathrm{N}^{\circ} 18.381$, de 17 de octubre de 2008), la información de clientes, la que puede ser objeto de propiedad intelectual y aquellas de naturaleza similar de acuerdo con to que establezcan los pliegos únicos o, en su caso, el pliego particular. No se consideran confidenciales los precios y las descripciones de bienes y servicios ofertados y las condiciones generales de la oferta.

Examinada la admisibilidad de las ofertas, a los efectos de determinar la oferta más conveniente a los intereses de la Administración pública y las necesidades del servicio, se tendrán en cuenta los factores de evaluación cuantitativos y cualitativos aplicables en cada caso, que deberán constar en el pliego de condiciones particulares.

Se deberá:

A) Prever razonablemente una ejecución efectiva y eficiente del contrato.

B) Obtener las mejores condiciones de contratación de acuerdo con las necesidades de la Administración.

C) Juzgar los antecedentes de los oferentes y el contenido de las ofertas en base a los criterios objetivos que se determinen en los pliegos".

La fuente del artículo 65 del TOCAF-2012 es la Ley $N^{\circ} 15.903$, de 10 de noviembre de 1987, artículo 504 con la redacción dada por el artículo 39 de la Ley $\mathrm{N}^{\circ} 18.834$ de 4 de noviembre de 2011. 
El problema en la práctica se plantea con el límite temporal en cuanto a la confidencialidad de información en las ofertas que son valoradas por las Comisiones Asesoras de Adjudicaciones.

En lo que refiere al tema que nos ocupa, este artículo contempla la posibilidad de que las ofertas contengan información confidencial siempre que sean entregadas en ese carácter (artículo 10 de la Ley N 18.381, de 17 de octubre de 2008), como por ejemplo la información de clientes, la que puede ser objeto de propiedad intelectual y aquellas de naturaleza similar de acuerdo con lo que establezcan los pliegos únicos o, en su caso, el pliego particular.

No se consideran confidenciales los precios y las descripciones de bienes y servicios ofertados y las condiciones generales de la oferta.

Si bien se admite la posibilidad de incluir en las ofertas información confidencial, la cuestión que se plantea en la práctica es hasta cuando temporalmente rige la misma, ya que en los hechos por ejemplo la información relativa a clientes puede ser uno de los ítems que la Comisión Asesora de Adjudicaciones actuante evalúe y pondere en cada una de las ofertas.

En este caso entendemos que, si la CAA ha valorado información confidencial de las ofertas y la ha ponderado y tenido en cuenta a los efectos de la elaboración del orden de prelación de los oferentes, deberá antes de notificar su dictamen a los oferentes, intimar a la empresa cuya oferta contenga información confidencial que ya sido valorada para que levante tal carácter, ya que en caso contrario la oferta, a nuestro juicio, deberá ser desestimada, por principios elementales de transparencia e igualdad de oportunidades, porque una vez que se notifique a los oferentes del orden de prelación, que será el fundamento principal de la posterior adjudicación, no puede haber impedimentos de ningún tipo para que los oferentes accedan al contenido total de todas las ofertas evaluados por la Comisión Asesora de Adjudicaciones para elaborar su Dictamen.

\section{CONFIDENCIALIDAD EN LOS PROCEDIMIENTOS DE COMPRAS Y CONTRATACIONES ESTATALES ELECTRÓNICAS: NUEVAS DIMENSIONES DE LA TRANSPARENCIA ANTE LOS AVANCES TECNOLÓGICOS, INFORMÁTICOS Y TELEMÁTICOS}

Carlos E. DELPIAZZO (1998) hace referencia a una dimensión tecnológica de la transparencia que refiere al advenimiento de los avances tecnológicos, informáticos y telemáticos en el ámbito público, que no sólo permiten nuevas modalidades de interacción entre la Administración y los administrados, y de manifestación de la voluntad administrativa, sino que permiten a los órganos 
públicos exhibir en tiempo real su accionar y así posibilitar nuevas formas de control y participación ${ }^{31}$.

Cada día es mayor la posibilidad de manejar herramientas informáticas como las computadoras, las redes de telecomunicaciones, Internet, los teléfonos celulares, los periódicos digitales, dispositivos portátiles, etc. Su utilización ha hecho más fácil y accesible la información, ha mejorado la comunicación, ha permitido reducir distancias geográficas e incluso en la actualidad representan nuevas formas de educación. El uso de toda esta nueva tecnología, su desarrollo e implementación, se denomina Tecnología de la Información y el Conocimiento (TIC), y es la base para la construcción del Gobierno Electrónico ${ }^{32}$.

Siguiendo estas tendencias modernas en el derecho comparado, sumamente arraigadas en la actividad privada en nuestro país y en forma incipiente en el sector público, la Agencia de Compras y Contrataciones Estatales define su misión y visión de acuerdo con tales lineamientos ${ }^{33}$.

-Misión 34: "La Agencia de Compras y Contrataciones del Estado promueve la mejora de gestión y la transparencia del sistema de compras y contrataciones del sector público, brindando asesoramiento para la generación de políticas públicas, el marco normativo, la tecnología, la capacitación necesaria y amplio acceso a la información generada".

-Visión ${ }^{35}$ : "Ser reconocida como un instrumento efectivo para la promoción, articulación y gestión de políticas públicas referidas a compras y contrataciones estatales y por la generación de confianza y transparencia en el sistema".

Tal como resulta de la lectura de la misión y visión de la Agencia de Compras, conceptos como la promoción de políticas públicas, la transparencia ${ }^{36}$ y la eficiencia se transforman en elementos recurrentes e imprescindibles para una mejora de la gestión del sistema de compras y contrataciones del sector público, tal

31. DELPIAZZO, C. E. (1998). Automatización de la actividad administrativa en el marco de la reforma del Estado. Anuario de Derecho Administrativo, 6, 17-28; p. 17 y siguientes.

32. SCHIAVI, P. (2012). El control del acceso a la información pública y de la protección de datos personales en el Uruguay. Montevideo: Universidad de Montevideo. Facultad de Derecho.

33. SCHIAVI, P. (2013). La Agencia de Compras y Contrataciones del Estado (ACCE): Desafios de una nueva gestión en las compras y contrataciones del Estado. Estudios de Derecho Administrativo, (8), 113-159.

34. http://www.comprasestatales.gub.uy/.

35. http://www.comprasestatales.gub.uy/.

36. SCHIAVI, P. (2012). El control del acceso a la información pública y de la protección de datos personales en el Uruguay..; loc. cit., p. 37 y siguientes. 
cual ha acontecido en otros países de la región (por ejemplo $\mathrm{Chile}^{37} \mathrm{Colombia}^{38}$, Costa Rica ${ }^{39}$, Ecuador $^{40}$, Panamá $^{41}$, Paraguay $^{42}$, Perú $^{43}$ ).

En esta materia, constituyen antecedentes de soluciones que se incorporan al nuevo TOCAF la aprobación del Decreto $\mathrm{N}^{\circ} 66 / 002$ de 26 de febrero de 2002, por el cual se estableció la obligación de enviar al sitio web identificado como "www. comprasestatales.gub.uy" los pliegos de bases y condiciones particulares de las licitaciones públicas o abreviadas que se realicen, así como las resoluciones de contrataciones directas que adopten los organismos públicos $\left(\operatorname{art.} 1^{\circ}\right)$.

El Decreto $\mathrm{N}^{\circ} 142 / 018$, de 14 de mayo de 2018, reglamenta los artículos 502, 503 y 504 de la Ley $N^{\circ} 15.903$ de 10 de noviembre de 1987, en el marco de lo dispuesto por los artículos 36 y 39 de la Ley $N^{\circ} 18.834$ de 4 de noviembre de 2011 (incorporados como artículos 63 y 65 del Texto Ordenado de Contabilidad y Administración Financiera del Estado (T.O.C.A.F.) aprobado por Decreto $N^{\circ} 150 / 012$ de 11 de mayo de 2012), en el marco de la reforma del régimen jurídico de las compras y contrataciones estatales.

Los mencionados artículos, de acuerdo con el RESULTANDO I) del Decreto referido, refieren al modo de apertura de las ofertas y su presentación, resguardando las mismas utilizando los procedimientos y tecnologías que aseguren la confidencialidad de la información de tal forma que sea inviolable hasta el momento fijado para su apertura, en cumplimiento del Decreto N$^{\circ} 275 / 013$ de 3 de setiembre de 2013, que reglamentó el régimen de apertura electrónica así como la presentación en línea de las ofertas, previendo la posibilidad de ser aplicado en cualquier procedimiento de contratación.

El Decreto $\mathrm{N}^{\circ} 142 / 018$ procura dotar al sistema electrónico de un protocolo de actuación que permita dar respuesta a las eventuales interrupciones que pudieran ocasionarse en el funcionamiento de este, asegurando un nivel de seguridad, transparencia y eficiencia en el procedimiento de contratación; de acuerdo con el CONSIDERANDO I).

De acuerdo con el artículo $1^{\circ}$, la Apertura Electrónica es una modalidad de gestión de los procedimientos de compras y contrataciones estatales que

37. Sitio Web de Chile Compra: http://www.chilecompra.cl/.

38. Sitio Web de Colombia Compra Eficiente: http://www.colombiacompra.gov.co/.

39. Sitio Web de Costa Rica Compra Red: https://www.hacienda.go.cr/.

40. Sitio Web de Ecuador Compras Públicas: https://www.compraspublicas.gob.ec/.

41. Sitio Web de Panamá Compra: http://www.panamacompra.gob.pa/.

42. Sitio Web de Paraguay Compras Públicas: https://www.contrataciones.gov.py/.

43. Sitio Web de Perú Sistema Electrónico: http://www2.seace.gob.pe/. 
permite, a través de una plataforma electrónica, la presentación, recepción, apertura y acceso a las ofertas.

El Artículo 2 establece el ámbito de aplicación al disponer que todas las administraciones públicas estatales pueden utilizar la modalidad de Apertura Electrónica en sus procedimientos de contratación. En los Incisos 2 al 15 del Presupuesto Nacional, las aperturas de los procedimientos competitivos de adquisiciones deberán efectuarse bajo esta modalidad. Exceptúase de la obligatoriedad dispuesta en el inciso anterior a aquellas adquisiciones que se realicen al amparo del artículo 37 del Texto Ordenado de Contabilidad y Administración Financiera del Estado (TOCAF). Exhórtase al resto de las Administraciones Públicas Estatales a utilizar la presente modalidad de apertura en sus procedimientos competitivos.

Dentro del sitio web de Compras y Contrataciones Estatales funcionará la plataforma electrónica a través de la cual se gestione la modalidad de Apertura Electrónica, la que deberá cumplir con las siguientes condiciones (Artículo $3^{\circ}$ ):

a. estar a disposición del público y ser compatible con las tecnologías de la información y de la comunicación de uso general;

b. ser capaz de recibir y almacenar la totalidad del contenido que refiere a una oferta;

c. admitir documentos en formatos abiertos y estándares, de amplio uso y generables con programas de fácil acceso o que, en su defecto, sean puestos a disposición de los interesados por parte del órgano contratante;

d. garantizar altos niveles de seguridad, disponibilidad y accesibilidad;

e. determinar con certeza la fecha y hora de recepción de las ofertas, así como la identidad del oferente, quien deberá estar registrado en el Registro Único de Proveedores del Estado;

f. garantizar que no pueda conocerse el contenido de las ofertas ni la identificación del oferente, hasta que expire el plazo previsto para su presentación;

g. habilitar solamente a personas autorizadas a fijar o modificar la fecha de apertura de las ofertas;

h. mantener la confidencialidad del contenido de las ofertas que el oferente ingrese en tal carácter; $y$

i. contar con un mecanismo de gestión para afrontar posibles problemas de funcionamiento del sistema, que permita reducir la probabilidad de ocurrencia e impactos negativos de estos, así como la reprogramación de fechas en caso de corresponder.

Para emplear la modalidad de Apertura Electrónica, la administración contratante deberá especificarlo en la invitación a cotizar y, en su caso, en el Pliego de Condiciones Particulares respectivo (Artículo 4). En el caso de modificar 
la opción mencionada, deberá dejarse sin efecto el llamado correspondiente e iniciarse uno nuevo.

El Artículo 5 regula la presentación de las ofertas al disponer que serán ingresadas a la plataforma electrónica por el oferente, quien deberá autenticarse ante el sistema informático respectivo, y estar inscripto en el Registro Único de Proveedores del Estado.

La documentación electrónica de la oferta se ingresará en los formatos indicados en el Pliego de Condiciones Particulares, sin contraseñas ni bloqueos para su impresión o copiado. Estos formatos deberán cumplir las características indicadas en el artículo 3 inciso c.

El Artículo 6 (Información confidencial) dispone "Cuando el oferente incluya información confidencial en su oferta, de conformidad con lo establecido en el artículo 65 del TOCAF, será de su exclusiva responsabilidad ingresar la misma indicando expresamente tal carácter, en archivo separado de la parte pública de su oferta.

En la parte pública de su oferta, deberá incluir un resumen no confidencial de la información confidencial que entregue (artículo 30 del Decreto $\mathrm{N}^{\circ} 232 / 010$ de 2 de agosto de 2010).

Los documentos que entregue un oferente en carácter confidencial no serán divulgados a los restantes oferentes".

Por su parte el Artículo 7 (Certificados y Muestras) establece que cuando el oferente deba agregar en su oferta un documento o certificado cuyo original solo exista en soporte papel, deberá digitalizar el mismo y presentarlo con el resto de su oferta. En caso de resultar adjudicatario, deberá exhibir el documento o certificado original, conforme a lo establecido en el artículo 48 del TOCAF.

De ser necesaria la presentación de garantías o muestras como parte de la oferta, las mismas se entregarán en la forma en que el organismo contratante lo indique en la invitación a cotizar o en el Pliego de Condiciones Particulares respectivo.

La Recepción de las ofertas está regulada en el artículo $8^{\circ}$.

La plataforma electrónica estará disponible para la recepción de ofertas las 24 horas todos los días hasta el momento fijado para la apertura de la convocatoria respectiva, la que deberá ser en día hábil en el horario definido por la Agencia de Compras y Contrataciones del Estado en el sistema.

La prórroga aprobada de la fecha de apertura solamente será válida una vez ingresada al sistema informático, permitiendo la recepción de ofertas hasta el vencimiento del nuevo plazo.

El Artículo 9 (Reserva de las ofertas) dispone que "No podrán conocerse las ofertas ingresadas a la plataforma electrónica, ni siquiera por la administración 
contratante, hasta tanto se cumpla la fecha y hora establecida para la apertura de las mismas".

La apertura de las ofertas se efectuará en forma automática y el acta será remitida por la plataforma electrónica a la dirección electrónica previamente registrada por cada oferente en el Registro Único de Proveedores del Estado. El acta de apertura permanecerá asimismo visible para todos los oferentes en la plataforma electrónica. Será de responsabilidad de cada oferente asegurarse de que la dirección electrónica constituida sea correcta, válida y apta para la recepción de este tipo de mensajes (Artículo $10^{\circ}$ ).

El acceso a las ofertas está regulado en el artículo $11^{\circ}$ : "A partir de la fecha y hora establecidas en el sistema para la apertura de las ofertas, éstas quedarán accesibles para la administración contratante y para el Tribunal de Cuentas, no pudiendo introducirse modificación alguna en las propuestas a partir de ese momento.

Asimismo, las ofertas quedarán visibles para todos los oferentes, con excepción de aquella información que sea entregada en carácter confidencial.

En caso de tratarse de un procedimiento que contemple la presentación de las ofertas separando el contenido técnico del económico, en la apertura mencionada en el inciso anterior se procederá a abrir únicamente el contenido técnico, reservándose la apertura del contenido económico para la instancia que indique el Pliego Particular, la que también se efectuará a través del sistema.

Solo cuando la administración contratante solicite salvar defectos o carencias de acuerdo a lo establecido en el artículo 65 del TOCAF, el oferente deberá agregar en línea la documentación solicitada".

En ocasión de su intervención, el Tribunal de Cuentas podrá acceder a las ofertas directamente a través del sistema, contando para ello con usuario especialmente habilitado a tales efectos (Artículo 12).

\section{REFLEXIONES FINALES}

La contratación administrativa es por esencia pública, lo cual implica que todos los procedimientos competitivos de contratación electrónicos que realicen las administraciones públicas deben ser transparentes y la información debe estar al alcance de todos los ciudadanos.

La información relativa a "Concesiones, licitaciones, permisos o autorizaciones otorgadas, especificando los titulares o beneficiarios de éstos" es esencialmente pública y más aún, es la información mínima que los sujetos obligados están obligados a publicar en los sitios webs oficiales sin necesidad que cualquier interesado la solicite (Ley N. ${ }^{\circ}$ 18.381, Art. 5 -2008- ). 
El principio de transparencia es, en nuestro derecho positivo, uno de los principios generales de actuación y contralor en materia de la Ley de Contabilidad y Administración Financiera.

Este principio de transparencia - sinónimo de la contratación administrativa - es el verdadero sostén de una contratación pública transparente, profesional y visible para toda la ciudadanía, principal escudo en la lucha contra la corrupción.

El acceso a la información es el principio, la limitación es de excepción.

Por tanto, las normas que limitan el acceso, como toda norma de excepción, son de interpretación estricta, regla que aplica sin lugar a dudas en sede de contratación administrativa.

Todos los límites al acceso a la información pública en sede de contratación administrativa en los procedimientos de contratación regulados en el TOCAF-2012 y en los procedimientos de compras y contrataciones estatales electrónicas deben ser valorados como normas de excepción y son de interpretación estricta.

Estado de Derecho, Democracia y Transparencia están últimamente vinculados, pues no puede haber ni Estado de Derecho, ni Democracia sin Transparencia.

\section{BIBLIOGRAFIA}

DELPIAZZO, C. E. (2019). Ciclo vital de las ofertas en los procedimientos de contratación administrativa electrónica. Revista de Derecho y Nuevas Tecnologías, 1, 189-204.

DELPIAZZO, C. E. (2019). Contratación administrativa. (ed.aum. y puesta al día). Montevideo: Fundación de Cultura Universitaria.

DELPIAZZO, C. E. (2015). ¿Contratación administrativa, estatal o pública? En: Comentarios al TOCAF: sobre la Contratación Pública. (pp.13-35). Montevideo: Universidad de Montevideo.

DELPIAZZO, C. E. (2015). Comentarios al TOCAF: sobre la Contratación Pública. Montevideo: Universidad de Montevideo. T.2.

DELPIAZZO, C. E. (2014). Procedimientos administrativos y nuevas tecnologías: A propósito de su nuevo marco normativo. Estudios de Derecho Administrativo, (10), 49-72.

DELPIAZZO, C. E. (2013). A propósito del tercer TOCAF En: Tratado jurisprudencial y doctrinario: actos y contratos de la administración. (pp.1139-1149). Montevideo: La Ley Uruguay.

DELPIAZZO C. E. (2003). De la publicidad a la transparencia en la gestión administrativa. Revista de Derecho Universidad de Montevideo, 113-124.

DELPIAZZO, C. E. (2005). Transparencia en la contratación administrativa. En: Liber amicorum discipulorumque José Aníbal Cagnoni. (pp.129-141). Montevideo: Fundación de Cultura Universitaria. 
DELPIAZZO, C. E. (1998). Automatización de la actividad administrativa en el marco de la reforma del Estado. Anuario de Derecho Administrativo, 6, 17-28.

DELPIAZZO, C. E. (1998). Marco Legal dela Automatización de la Actividad Administrativa: El 'expediente electrónico' en Uruguay. Informáticay Derecho: Revista Iberoamericana de Derecho Informático, (19-22), 699-720. Presentado en Jornadas Marco Legal y Deontológico de la Informática (Mérida: 16-20 set. 1997).

DURÁN MARTÍNEZ, A. (2018). Principios rectores de la contratación administrativa. Incidencia en la ejecución de los contratos administrativos. Estudios de Derecho Administrativo, (17), 5-39.

DURÁN MARTÍNEZ, A. (2014). El contrato administrativo en Uruguay. Estudios Jurídicos, (12), 117-191.

DURÁN MARTÍNEZ, A. (2013). "Principios de la contratación administrativa". Estudios de Derecho Administrativo, (8), 49-85.

DURÁN MARTÍNEZ, A. (2013). Licitación pública. Estudios de Derecho Administrativo, (8), 161-193.

DURÁN MARTÍNEZ, A. (2012). Derecho a la protección de datos personales y al acceso a la información pública hábeas data: Leyes no. 18.331, de 11 de agosto de 2008 y no. 18.381, de 17 de octubre de 2008. (2a.ed.act.ampl). Montevideo: Amalio M. Fernández.

DURÁN MARTÍNEZ, A. y SCHIAVI, P. (2013). Texto Ordenado de la Contabilidad y Administración Financiera del Estado (TOCAF). Estudios de Derecho Administrativo, (8), 825-915.

RISSO FERRAND, M.J. (2011). Los principios generales de la contratación administrativa en Uruguay: con especial referencia al principio de igualdad y principio del respeto del pliego. En: Estudios jurídicos en Homenaje al Profesor Juan Pablo Cajarville Peluffo. (pp.373-389). Montevideo: Fundación de Cultura Universitaria.

RODRÍGUEZ-ARANA, J. (2016). Los principios del derecho global de la contratación pública. Revista de Derecho: Publicación Arbitrada de la Universidad Católica del Uruguay, [Recurso en línea], 12(13), 189-217.

SCHIAVI, P. (2013). La Agencia de Compras y Contrataciones del Estado (ACCE): Desafíos de una nueva gestión en las compras y contrataciones del Estado. Estudios de Derecho Administrativo, (8), 113-159.

SCHIAVI, P. (2019). Estudios de información pública y datos personales: doctrina y jurisprudencia destacada. Recopilación de trabajos de los cursos de postgrado 2016-2018. Montevideo: Universidad de Montevideo. Facultad de Derecho. T. 3.

SCHIAVI, P. (2016). Estudios de información pública y datos personales: recopilación de trabajos de investigación de los cursos de postgrado 2014-2015. Montevideo: Universidad de Montevideo. Facultad de Derecho. T.2.

SCHIAVI, P. (2014). Estudios de información pública y datos personales: recopilación de trabajos de investigación de los cursos de postgrado 2012-2013. Montevideo: Universidad de Montevideo. Facultad de Derecho. [T.1] 
SCHIAVI, P. (2019). Estudios de Derecho Administrativo Disciplinario: doctrina y jurisprudencia destacada. Recopilación de trabajos del Curso de postgrado 2018. Montevideo: Universidad de Montevideo. Facultad de Derecho. T.1.

SCHIAVI, P. (2016). Régimen jurídico de la acción de acceso a la información pública en el Uruguay. En: Estudios de información pública y datos personales: recopilación de trabajos de investigación de los cursos de postgrado 2014-2015. (pp.21-61). Montevideo: Universidad de Montevideo. Facultad de Derecho.

SCHIAVI, P. (2016). Límites al acceso a la información pública en la Administración Nacional de Telecomunicaciones (Antel). En: Estudios de información pública y datos personales: recopilación de trabajos de investigación de los cursos de postgrado 2014-2015. (pp.347-363). Montevideo: Universidad de Montevideo. Facultad de Derecho.

SCHIAVI, P. (2014). Procedimiento administrativo especial: Ruta de acceso a la información pública. Estudios de Derecho Administrativo, (10), 399-424.

SCHIAVI, P. (2014). Límites al acceso a la información pública en la minería de gran porte. Estudios de Derecho Administrativo, (9), 381-395.

SCHIAVI, P. (2014). Reflexiones a cinco años de la ley de acceso a la información pública en Uruguay. En: Estudios de información pública y datos personales: recopilación de trabajos de investigación de los cursos de postgrado 2012-2013. (pp.19-40). Montevideo: Universidad de Montevideo. Facultad de Derecho. Presentado en 6to. Encuentro Nacional de Gobierno Electrónico (Montevideo: 4-5 dic. 2013)

SCHIAVI, P. (2012). Decreto No. 17/012 de 26 de enero de 2012. Estudios de Derecho Administrativo, (6), 541-597.

SCHIAVI, P. (2013). La Agencia de Compras y Contrataciones del Estado (ACCE): Desafíos de una nueva gestión en las compras y contrataciones del Estado. Estudios de Derecho Administrativo, (8), 113-159.

SCHIAVI, P. (2012). Ley No. 18.786 de 19 de julio de 2011. Estudios de Derecho Administrativo, (6), 491-538.

SCHIAVI, P. A. B. L. O. (2012). Marco legal y organizativo de la Participación Público-Privada: Desafíos de una nueva institucionalidad. Estudios de Derecho Administrativo, (6), 83-125.

SCHIAVI, P. (2012). Límites al acceso a la información pública en la participación Público-Privada. Estudios de Derecho Administrativo, (6), 617-637.

SCHIAVI, P. (2012). El control del acceso a la información pública y de la protección de datos personales en el Uruguay. Montevideo: Universidad de Montevideo. Facultad de Derecho.

SCHIAVI, P. (2012). La participación público-privada en el desarrollo de infraestructuras y servicios relacionados en el Uruguay: Primeras reflexiones sobre la Ley No. 18.786. Revista de Derecho y Tribunales, (18), 119-147. Presentado en 4a. Jornadas de Derecho Administrativo Iberoamericano (La Coruña: 30 mayo-3 jun. 2011). 
SCHIAVI P. (2011). El acceso a la información pública en el Uruguay. Estudios de Derecho Administrativo, (3), 391- 434.

VÁZQUEZ, C. y SCHIAVI, P. (2013). Procedimientos administrativos: Decreto 500/991 de 27 de setiembre de 1991. Montevideo: La Ley Uruguay. T.1.

VÁZQUEZ, C. (2011). El régimen jurídico del acceso a la información pública y la protección de los datos personales. Revista de Derecho y Tribunales, (15), 59-109.

\section{Pesquisas do Editorial}

\section{Veja também Doutrinas relacionadas ao tema}

- Das regras de governança corporativa, transparência e gestão de riscos, de Sergio Ferraz - RDAl 7/109-137 (DTR|2018|22481);

- La adopción de pliegos de condiciones tipo como herramienta para la promoción de la transparencia y la competencia en el sistema de compra pública colombiano, de Juan David Duque Botero - RDAl 10/121-140 (DTR|2019|39998); e

- Publicidade e transparência nas parcerias voluntárias, de Ricardo Marcondes Martins - RDAl 13/59-97 (DTR|2020|6390). 